\title{
A Case Report of Dental Abscess affecting Facial Skin
}

Amir Khalid Hassan*

QAF, Medical Services, Doha, Qatar, University of Baghdad, Iraq

\begin{abstract}
Some neck or face lesion might confused the physicians in its origin especially if it is dentally involved. A good teamwork treatment is essential to discover such as lesion and even in the treatment to finalize the case properly by cosmetic dermatological treatment using lazer. The importance of irrigation solution with broad spectrum antibiotic such as doxycycline with chloroheidine mouthwash is equal to proper root canal preparation in the success of treatment of such extensive periapical lesions.
\end{abstract}

Keywords: Facial skin; Periapical lesions; Dental infections

\section{Introduction}

Dental abscess is frequently found in oral cavity [1]. It is frequently related with badly treated carious tooth and poor oral hygiene. Dental caries and pulp necrosis often ended in extending the infections to alveolar bone and sometimes involving the outer layer of the face (sinus) [1-9]. This facial sinus orifice cannot be distinguished easily in its origin, confusing the medical team [2-10]. A fistula is an abnormal pathway between 2 anatomic spaces or a pathway that leads from an internal cavity or organ to the surface of the body. A sinus tract is an abnormal channel that originates or ends in one opening. An orofacial fistula is a pathologic communication between the cutaneous surface of the face and the oral cavity.

In the literature, the terms fistulas and sinuses are often used interchangeably. Stedman's Medical Dictionary defines a sinus as a fistula or tract leading to a suppurating cavity. Orofacial fistulas are not common, but intraoral sinus tracts due to dental infections are common. When infection or neoplasia is involved, immediate treatment is necessary. Dental infections, salivary gland lesions, neoplasms, and developmental lesions cause oral cutaneous fistulas, fistulas of the neck, and intraoral fistulas $[2,3,5]$.

Chronic dental periapical infections cause the most common intraoral and extraoral fistulas. These dental periapical infections might cause chronic osteomyelitis, cellulitis, and rarely facial abscesses. Infection can spread to the skin when it is the path of least resistance then causing cutaneous fistulas.

One case report reviewed this occurrence from a periapical infection from the right central mandibular incisor, which drained to the patient's chin. Because the tooth could not be restored, it was extracted, which resolved the lesion.

Another case with cutaneous manifestations involved a 44-year-old woman with a draining lesion to the skin just lateral to the nasofacial sulcus. Oral antibiotics did not help treating the lesion. The patient had bad oral hygiene, and two periapical radiolucencies of the maxillary right lateral incisor and canine were observed. The teeth were extracted, which resolved the lesion. Sheehan et al. emphasized on the importance of a dental examination and radiographs to rule out infection of dental origin to the cutaneous face or neck.

This case- study showed three cases of intra-oral abscess extending through the bone and facial skin.

\section{Case 1}

A 20-year-old Yemeni patient visited many doctors only when the abscess came out from her face. Drainage and curettage has been performed by General Physicians as well as laser cauterization by Dermatologist. Lately, it was suspected that it might be of dental origin.

The patient was referred to Dental Department. Root canal treatment on upper right first molar has initially been done 3 years ago (2010) but it is not completed. Therefore, she suffered from chronic periapical abscess in which intrapulpal drainage has been made with antibiotics for several times and left open with no further treatment. During the examination it was noticed that the abscess extended to the face and was drained through infraorbital skin area (Figure 1)

Radiographical examinations were done by orthopantogram and periapical parallel technique inserting the gutta percha cone inside the facial orifice of the sinus and tracking the origin of it. These revealed the presence of this abscess and its relation to the suspected tooth.

A case has been discussed fully to the patient, as well as the poor prognosis of the tooth treatment. Full root canal therapy preparation

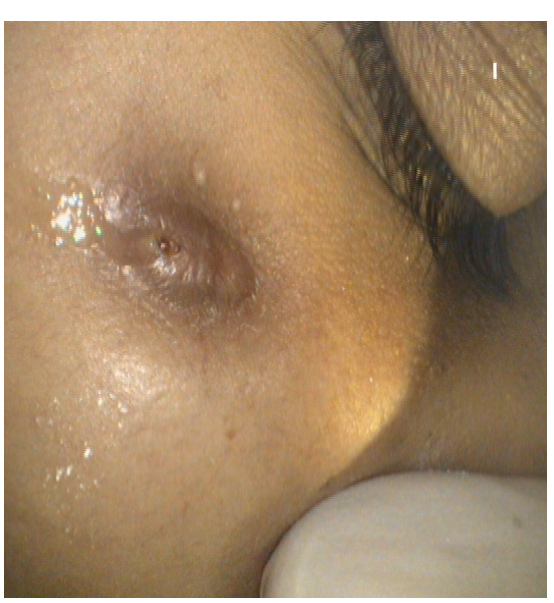

Figure 1: The facial lesion showing the pus and then the irrigation solution coming out of the facial lesion.

*Corresponding author: Dr. Amir Khalid Hassan, BDS/MDS, QAF, Medical Services, Doha, Qatar, formerly assistant prof. at Dental college, University of Baghdad, Iraq, Doha 24478, QATAR, Tel: 0097455835687; E-mail: amiralagidi@gmail.com

Received April 27, 2018; Accepted May 10, 2018; Published May 15, 2018

Citation: Hassan AK (2018) A Case Report of Dental Abscess affecting Facial Skin. Dentistry 8: 488. doi:10.4172/2161-1122.1000486

Copyright: ( 2018 SHassan AK. This is an open-access article distributed under the terms of the Creative Commons Attribution License, which permits unrestricted use, distribution, and reproduction in any medium, provided the original author and source are credited. 
and obturation using protaper system was done through three visits of 10 days interval and under antibiotic coverage of Doxycycline capsule $150 \mathrm{mg}$ twice a day orally systematically. The same antibiotic tablets (3 tabs) were crashed into a chlorohexidine mouthwash and used as irrigant for the root canals along the procedures (Figure 2).

The case has been observed for three months (Figures 3 and 4) six months (Figure 5) and one year without any complaints. The tooth is finally restored with a ceramic crown.

The outer scar of the sinus was treated by laser and it is nearly disappeared.
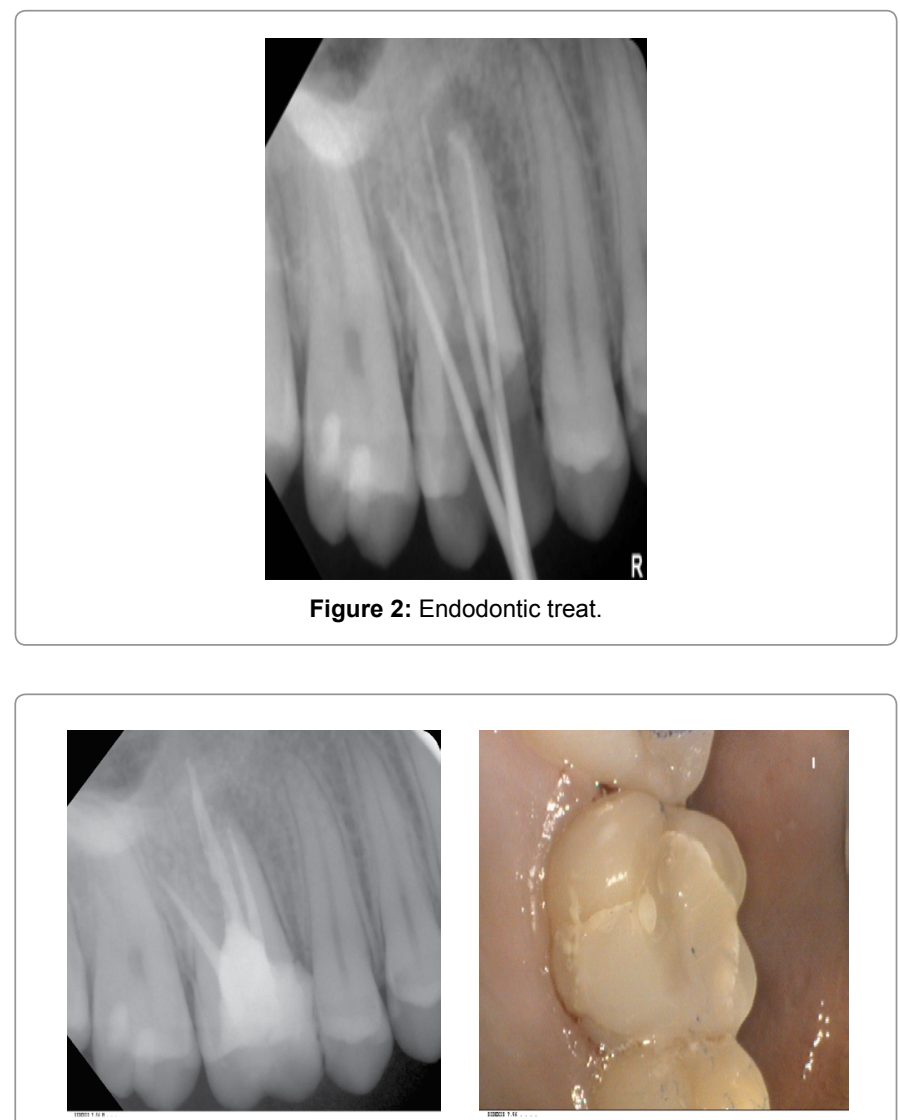

A

B

Figure 3a\&b: After 3 months

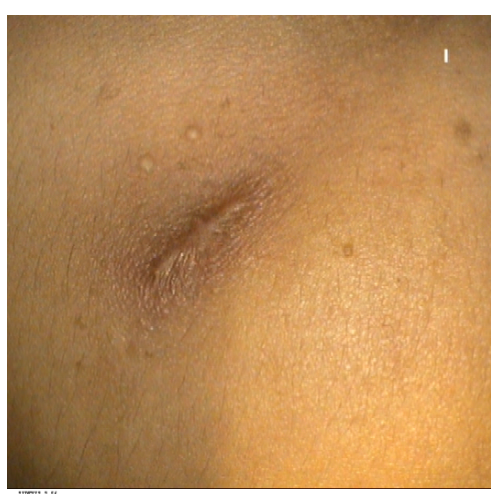

Figure 4: After 3 months.

\section{Case 2}

A 22-year-old Pakistani female patient was complaining of recurrent excised skin infection at the neck with purulent discharge from the corner of the mandible. She went to medical physicians many times and ended by surgical excision of the granulation tissue at the neck with many courses of antibiotic with no use.

She attended the facility of Qatar Armed Forces where she was referred to Dental Department for consultation. Full oral examination was carried out, $\mathrm{x}$-ray views using an old technique of inserting gutta percha cone inside the outer neck skin lesion revealing that its origin is related to the root of lower left 6 (LL 6) which is found badly carious, infected and poor prognosis (Figures 6-8). The same method of treatment in case 1 was followed. The skin lesion was subsided and disappeared, leaving a light scar (Figures 9-12). Evaluation for the case was made for one, three months, six months and a year with progressive success. The patient refused to do laser treatment to remove the scar as lesion become shallow and not recognizable.
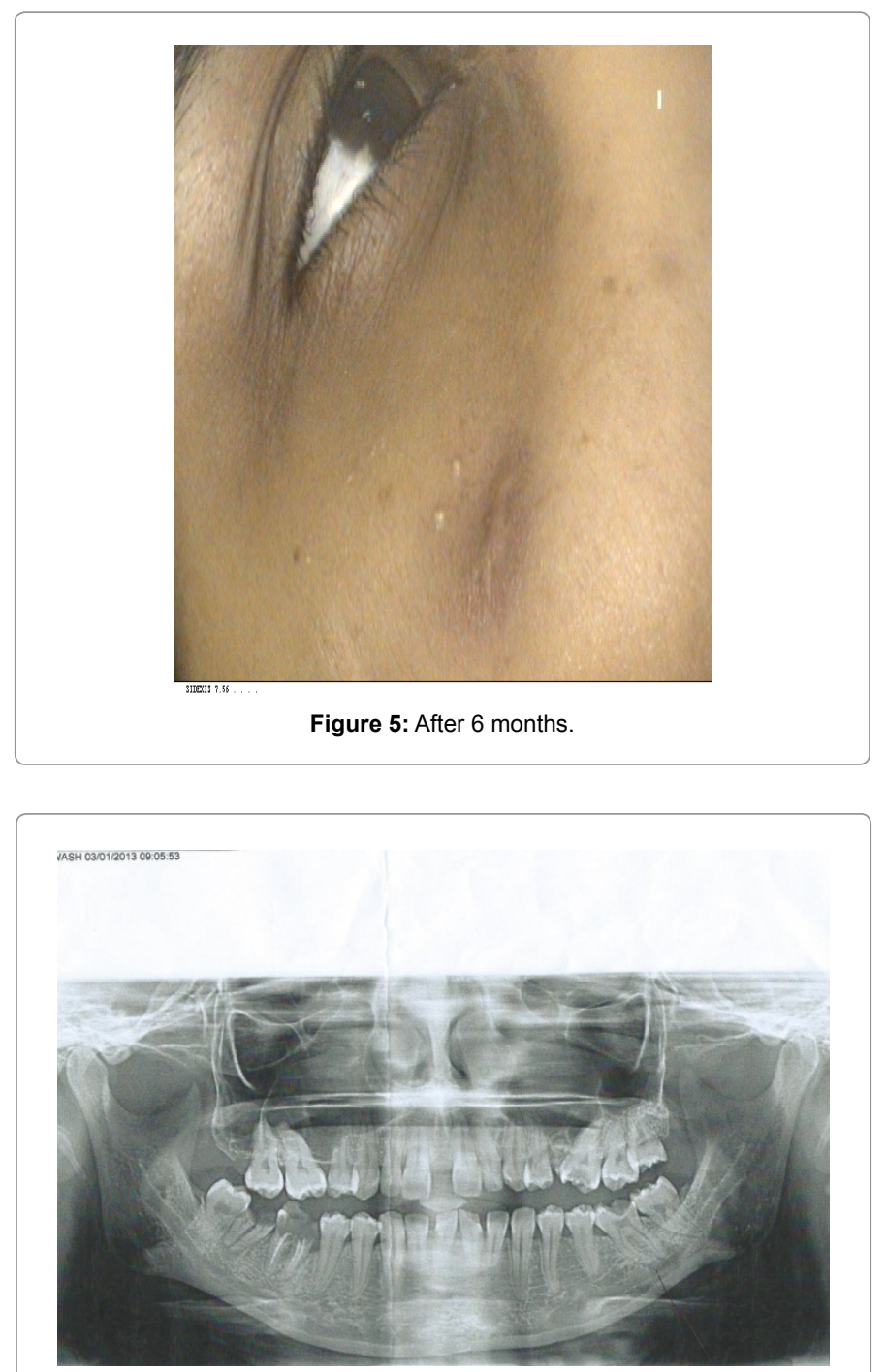

Figure 6: Pre-operative OPG showing LL 6 with active and extended periapical lesion 
$\mathbf{A}$

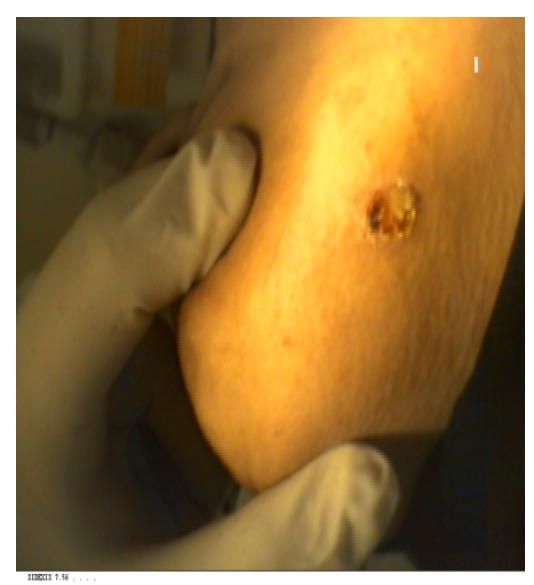

B
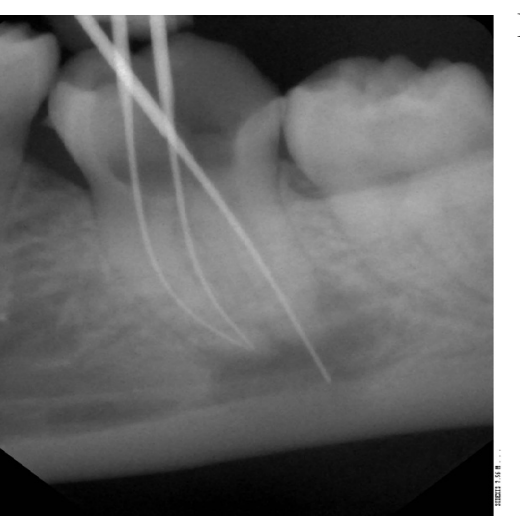

$\mathrm{C}$

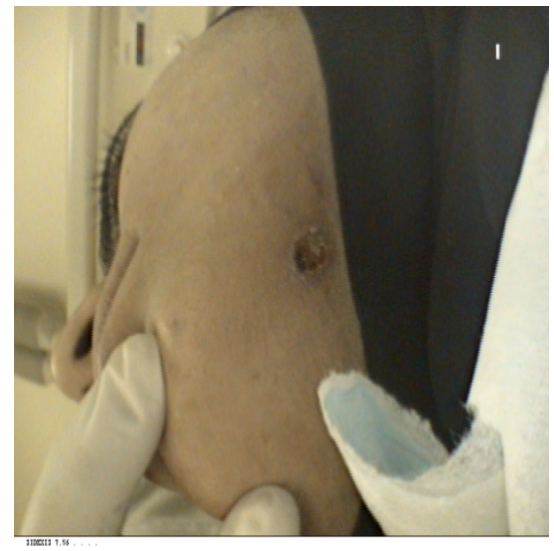

$\mathrm{D}$

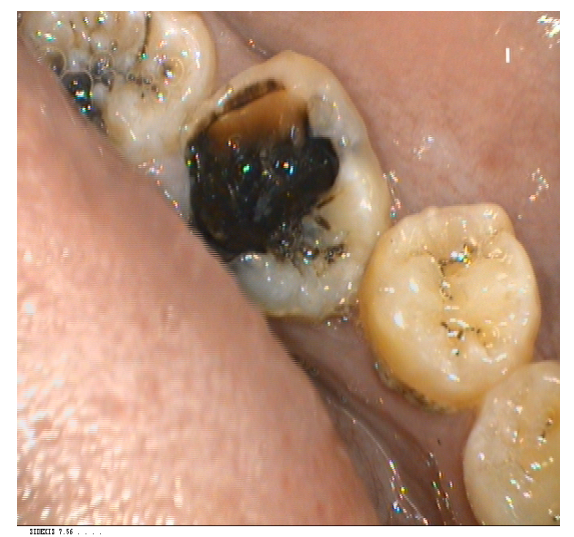

Figure 7(A,B,C,D): Photograph showing the clinical features of the facial lesion and the oral status of the affected tooth.

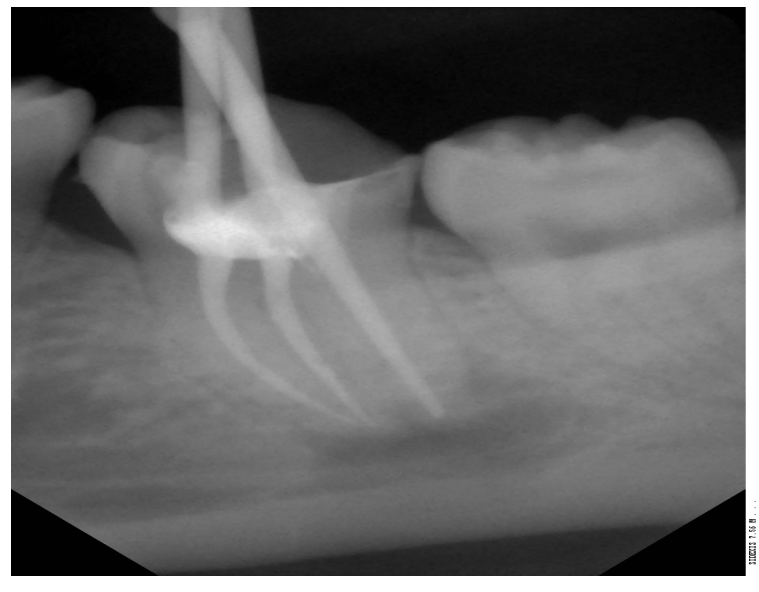

Figure 8: The finished treated tooth.

\section{Case 3}

A Pakistani female (62 years old) patient had been referred from dermatology clinic suffering from discharging nodule on the right lower nasiolabial fold since more than two months. She took many courses of antibiotics and surface lozenges with no benefits. Patient is diabetic as well as hypertensive and controlled medically. Oral and dental examination was carried using clinical and radiological investigations, she was wearing a complete fixed prostheses from molar

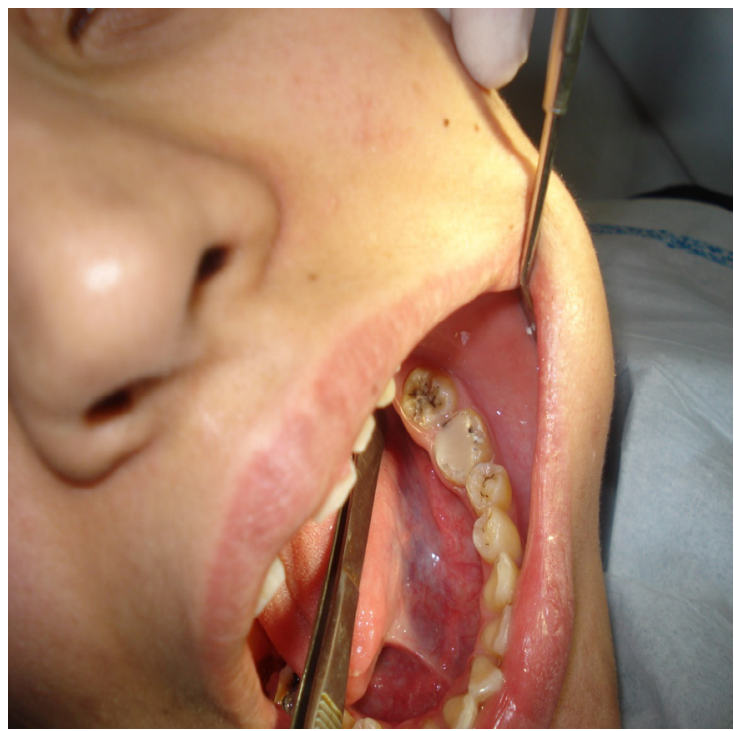

Figure 9: The tooth when oburated

to molar. A (GP) point inserted inside the facial nodule shows clearly that the nodule is related to the apical abscess of the RCF routine. Work was made through the prostheses to clear the pathological tissue. It was shown during the irrigation procedure of RCF, the solution comes out 
of the nodule sinus. fucidine cream to cover the facial sinus. Irrigation was made by Doxicycline capsule solved in $500 \mathrm{ml}$ of Saline. The patient kept monitoring and irrigated every week, for 3 weeks, the facial sinus completely closed, the radioapacity of the periapical area of the specified tooth reduced to minimum, and obturation is done by Gutta Perchas as routine. The patient followed up to after $2-3$ months until successful healing of facial sinus (Figures 13-15).
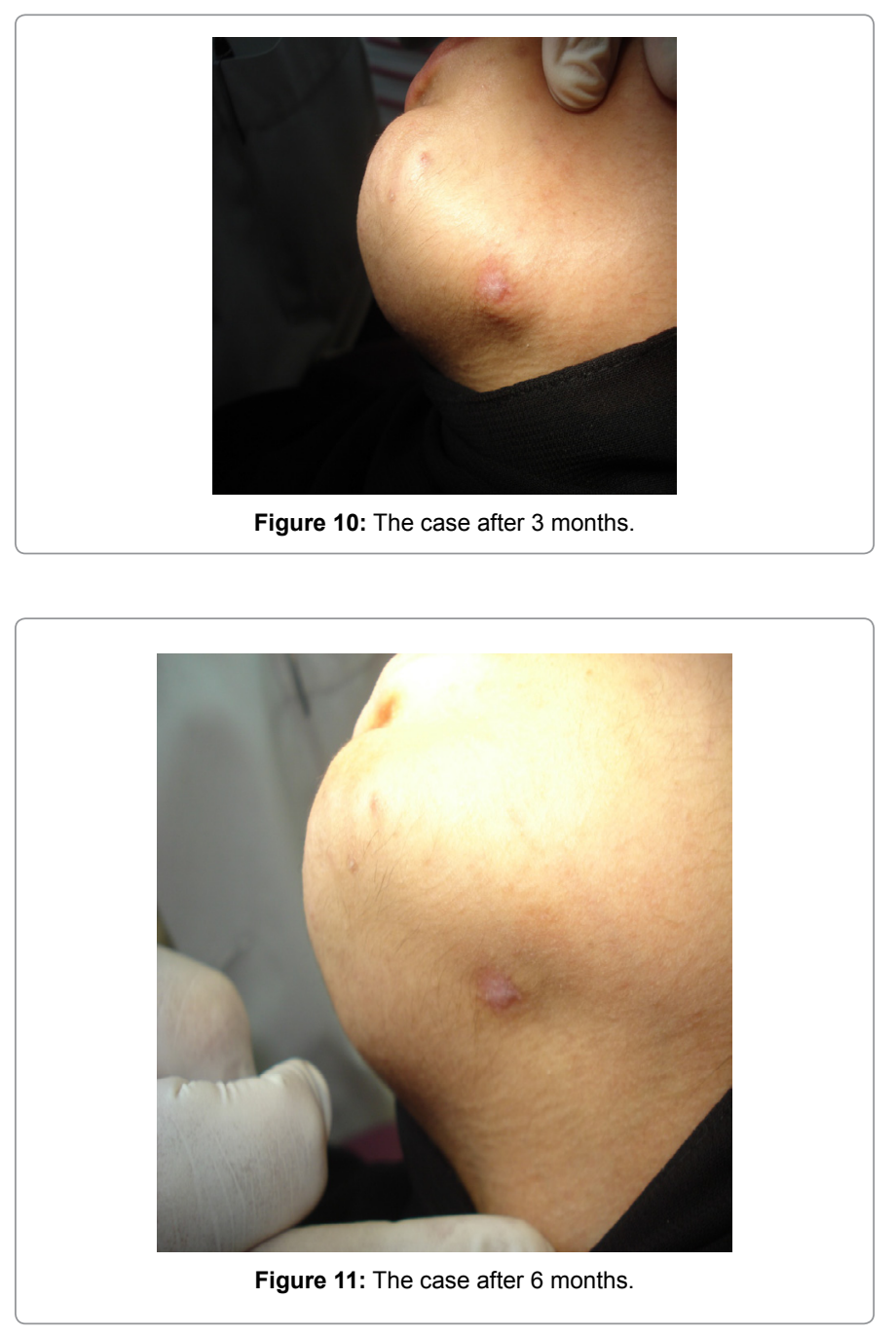

A

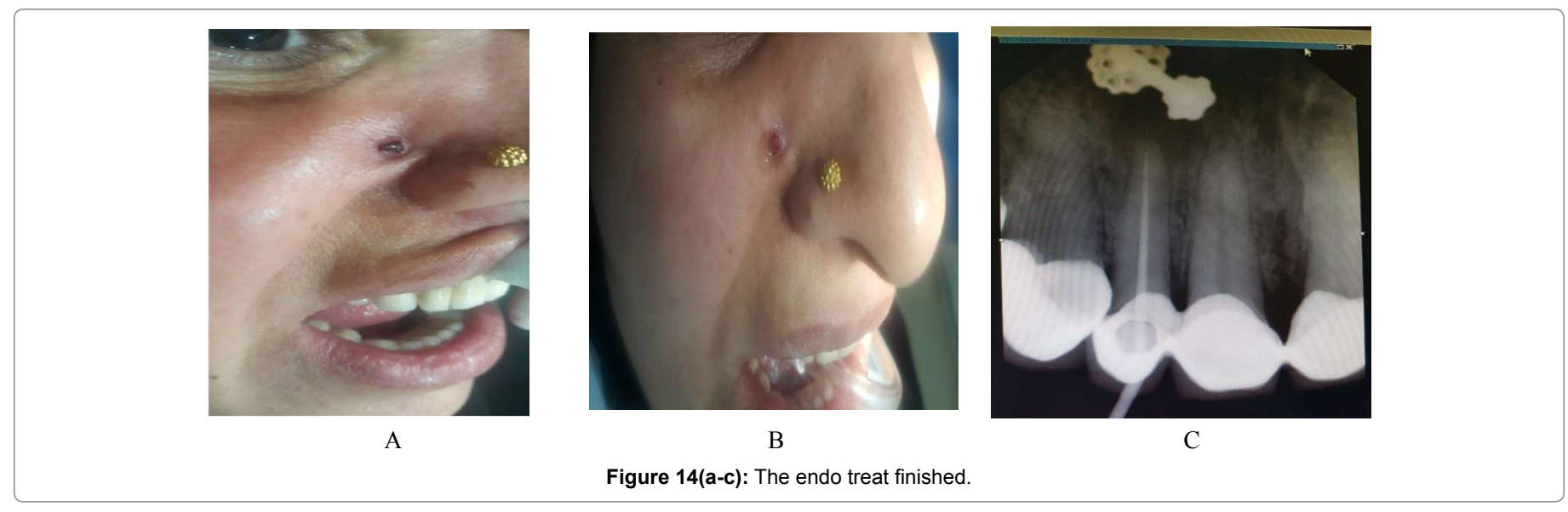

B

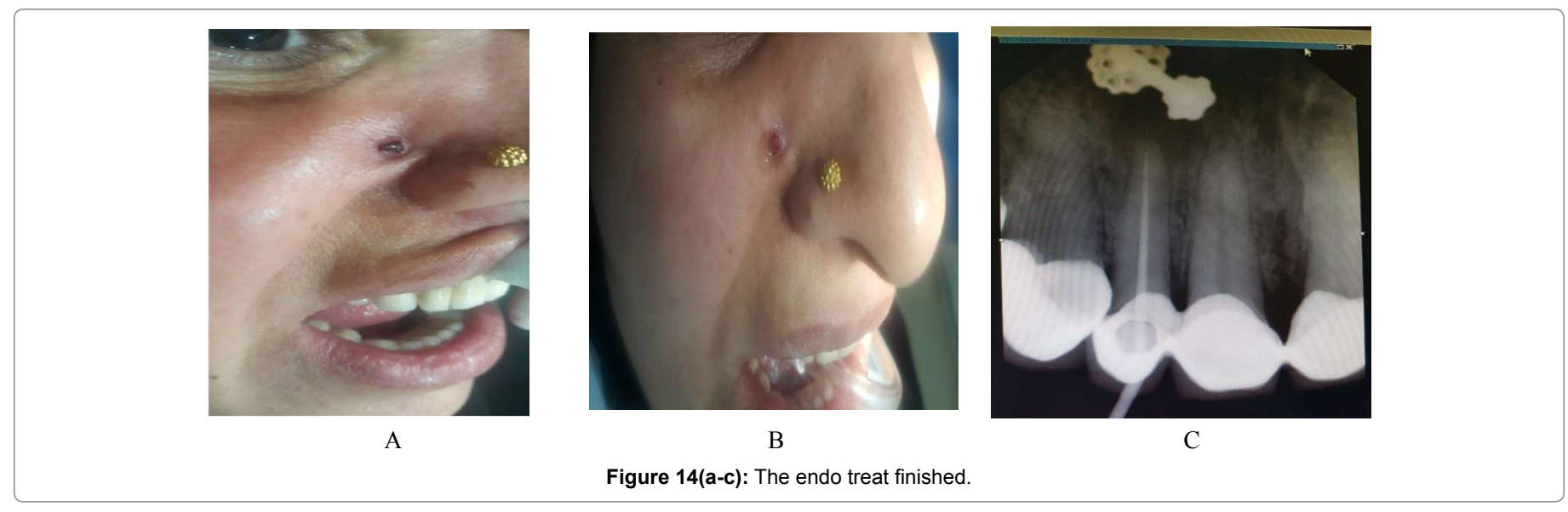

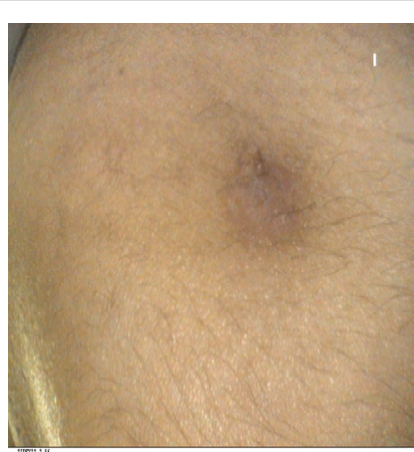

Figure 12: The case after 12 months.

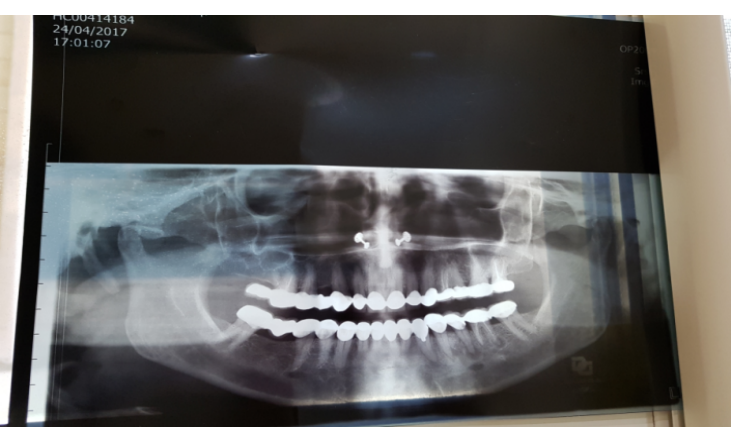

A

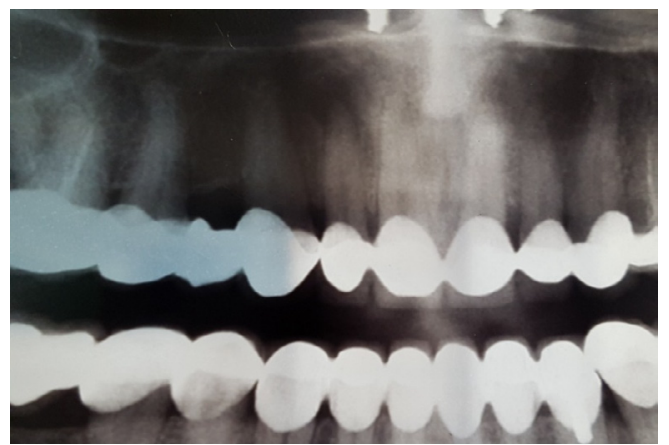

Figure 13(a\&b): Clinical appearance and orthopantogram for the case ,note the irregation fluid coming out of the lesion. 


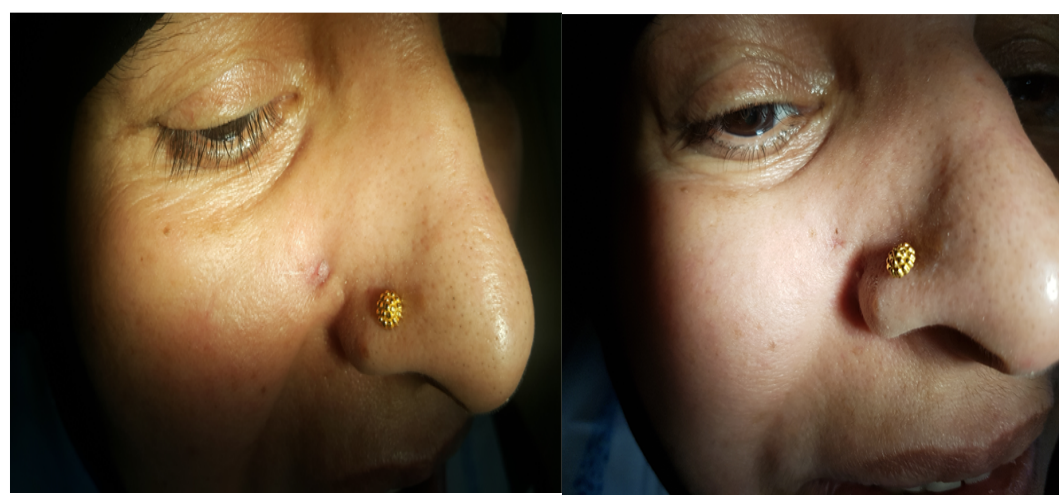

A

B

Figure 15: The case finished, followup after 21 days (a) 1 month and (b) 2 months.

\section{Conclusion}

Some neck or face lesion might confused the physicians in its origin especially if it is dentally involved. A good teamwork treatment is essential to discover such as lesion and even in the treatment to finalize the case properly by cosmetic dermatological treatment using lazer. The importance of irrigation solution with broad spectrum antibiotic such as doxycycline with chloroheidine mouthwash is equal to proper root canal preparation in the success of treatment of such extensive periapical lesions.

\section{References}

1. Neville, Brad W 1995 Oral and Maxillofacial Pathology. Saunders 104-105.

2. Cantatore JL, Klein PA, Lieblich LM (2002) Cutaneous dental sinus tract, a common misdiagnosis: a case report and review of the literature. Cutis 70 : 264-267.

3. Sheehan DJ, Potter BJ, Davis LS (2005) Cutaneous draining sinus tract of odontogenic origin: unusual presentation of a challenging diagnosis. South Med J 98: 250-252.
4. Gound TG, Maixner D (2004) Nonsurgical management of a dilacerated maxillary lateral incisor with type III dens invaginatus: a case report. J Endod 30: $448-451$.

5. Nallapati S (2004) Clinical management of a maxillary lateral incisor with vital pulp and type 3 dens invaginatus: a case report. J Endod 30:726-731.

6. Steffen $\mathrm{H}$, Splieth $\mathrm{C}(2005)$ Conventional treatment of dens invaginatus in maxillary lateral incisor with sinus tract: one year follow-up. J Endod 31 : 130-133.

7. Sert S, Bayrl G (2004) Taurodontism in six molars: a case report. J Endod 30 601-602.

8. Yasui H, Yamaguchi M, Ichimiya M, Yoshikawa Y, Hamamoto Y, et al. (2005) A case of cutaneous odontogenic sinus. J Dermatol 32: 852-855.

9. Gonçalves M, Pinto Oliveira D, Oliveira Oya E, Gonçalves A (2002) Garre's osteomyelitis associated with a fistula: a case report. J Clin Pediatr Dent 26 311-313.

10. Gerhards F, Büttner R, Jänicke S (2001) Aberrant salivary gland tissue in differential diagnosis of branchiogenic neck cyst. HNO 49: 476-478. 